\title{
No reino da palavra: reflexões sobre a leitura literária
}

Saulo Lopes de Sousa*

\section{Resumo}

Este artigo versa sobre a temática "Leitura literária". Discutem-se a concepção de leitura literária, os mecanismos utilizados pelo professor no ensino de literatura, as formas inadequadas de uso do texto literário e a importância do fenômeno literário na formação do indivíduo. Percebe-se que leitura e literatura são duas áreas complementares que, juntas, promovem a formação contínua do ser. Posto que literatura é arte, é preciso haver a consciência do papel estético desempenhado pelo texto literário, bem como o respeito a essa função, por meio do tratamento dispensado pela escola ao letramento literário. Fundamentam esse estudo, dentre outras, as teorias de Aguiar (2006), Cereja (1995), Frantz (2005), Freire (1989), Lajolo (1982) e Zilbernam (2009).

Palavras-chave: Leitura literária; Ensino de literatura

\section{The kingdom of the word: reflections about literary reading}

\begin{abstract}
This article focuses on the theme "literary reading". Discusses the conception of literary reading are woven, the mechanisms used by the teacher in teaching literature, inadequate methods of use of the literary text and the importance of the literary phenomenon in the formation of individual. It is noticed that reading and literature are two areas that are complementary and together promote the continuous training of being. Since literature is art, there needs to be awareness of the aesthetic role of the literary text as well as respect to this function by the treatment meted out by the school literary literacy. Underlying this study, among others, theories Aguiar (2006), Cereja (1995), Frantz (2005), Freire (1989), Lajolo (1982) and Zilbernam (2009).
\end{abstract}

Key-Words: Literary reading; Teaching of literature

\section{Introdução - porque ler é preciso!}

Ler é um mergulho no insondável de nós mesmos, é como pescar a pérola que trazemos suspensa na alma. Ler é aventurar-se na descoberta da própria essência.

Antonio Coutinho

"A Literatura é o sonho acordado das civilizações". A maestria com que Antônio Cândido define a gênese da arte literária abre portas para o desvendar da grandeza contida na literatura. Mais do que proporcionar a simples leitura de um texto, o caráter

\footnotetext{
* UEMA - Universidade Estadual do Maranhão. Faculdade de Letras. Imperatriz. Maranhão. Brasil. Email: saulolopes_sousa@hotmail.com
} 
literário de uma obra permite ao leitor transcender o reconhecimento da manifestação artística. Ele passa a traduzir um interesse pelo que é humano, aludindo emoções e anseios. Assim, esse contato humaniza o leitor, torna-o cidadão. A função da literatura não é meramente histórica - ainda que seja o retrato de uma época e sociedade - ou mesmo lúdica. Sua importância reside no fato de permitir ao leitor descobrir outros universos, ver outros mundos, experimentar outras vidas, estabelecer outras visões. Por meio da leitura da obra literária, o homem compreende a trajetória humana e, compreendendo-se, abandona sua ignorância e passa do "inferno ao paraíso".

A literatura (latim littera, "letra") sempre fez parte da vida humana como expressividade artística mediante a palavra, até mesmo nas sociedades primitivas, em que não existia a escrita, no caso, a partir das pinturas rupestres ou da poesia oral. De acordo com Cereja (1995, p.10), "Literatura é a arte da palavra”. Desse modo, tomando a literatura como instância estética e a palavra como elemento basilar da língua, pode-se dizer que a literatura, da mesma forma como a língua de que se vale, é um mecanismo de comunicação e, sendo assim, desempenha ao mesmo tempo a função social de transmissão de conhecimentos e cultura de um povo. Ainda que esteja vinculada a uma língua, que lhe é sustentáculo, a literatura não se prende a esta, mas a utiliza livremente, podendo inclusive rebelar suas normas e o significado do código linguístico.

O fazer literário do escritor assemelha-se ao trabalho do oleiro, cujas mãos, molhadas de fantasia, moldam as curvas do artesanato da palavra. E este só existirá na medida em que for (re)moldado pelas mãos úmidas de fantasias do leitor. Além de manifestar a fantasia e a imaginação, o texto literário evoca sensibilidade, tanto de emoções como de linguagens. A aventura pelas veredas do texto literário possibilita a educação da própria sensibilidade, por meio das práticas de leitura. Por isso, a literatura é de suma relevância para que se desvie da constituição de um sujeito pela metade, e isso vale não só para a educação básica, mas para a Educação de modo geral.

Não há literatura inocente, como também não existe autor ingênuo. Não se faz literatura sem um propósito. E aquele que toma o texto literário numa situação de causalidade, por certo, passará pelo mesmo sem que o tenha descoberto, invalidando o intento transformador que reside na obra. A leitura e escrita literárias são formas de ler e escrever a existência humana, conferindo-lhe sentido. Por meio da literatura, o leitor (re)conhece a si mesmo e ao mundo, pois é a vida o pano de fundo da criação literária: 
O contato com a literatura resulta sempre num ganho para o leitor. Tanto faz se ela confirma expectativas ou abala convicções. Fica invariavelmente um saldo de conhecimento acerca de si e do mundo, uma perspectiva inusitada ou uma forma diferente de ele se autoconhecer e de interagir com a realidade (AGUIAR, 2006, p.210).

A ação da leitura, neste caso da leitura literária, está sempre sujeita às experiências do leitor, adquiridas ai longo de sua jornada terrena. Toda atividade, e inclui-se aqui o ato de ler, processa-se mediante a convivência com o próprio mundo. Conforme Paulo Freire (1989), anterior à vida escolar e ao primeiro contato com o mundo das palavras, existe a leitura do mundo, que circunda nosso entorno: "A leitura do mundo precede a leitura da palavra, daí que a posterior leitura desta não possa prescindir da continuidade da leitura daquele" (p.09).

\section{Leitura literária na escola: entraves e desafios}

No que tange ao ensino da leitura literária no âmbito escolar, verifica-se que as discussões em torno da mesma têm se preocupado em angariar a relevância e o merecido espaço da literatura na sala de aula. Contudo, têm-se privilegiado outras atividades, relegando a leitura literária à margem do ensino de Língua Portuguesa, tornando o mesmo automático e desinteressante. Tal postura é resultando de concepções tradicionalistas que não produzem no aluno nenhum resultado satisfatório, pelo contrário, se afasta da realidade dos mesmos e não os considera princípio do qual se possa partir para a concretização de um ensino literário consistente.

Paulo Freire assinala que "a leitura da palavra não é apenas precedida pela leitura do mundo, mas por uma certa forma de escrevê-lo, quer dizer, de transformá-lo através de nossa prática consciente" (1989, p.20). Nessa perspectiva, o ato de ler não deve se restringir ao decurso da leitura, mas difundir-se por todas as instâncias, não deixando de lado a ótica do texto lido. A partir desse momento, a leitura literária exerce outra função e se permuta no exercício de constituição do sujeito. É importante pontuar que a leitura de mundo - principiadora da leitura literária - deve caracterizar-se pela criticidade, na medida em que indivíduo e sociedade interagem e se constituem, mediados pelas experiências interpessoais e culturais.

Leitura literária, assim, alegoriza uma colheita de conhecimentos, consoante Vargas: "ler significa sempre um ato de compreender, estabelecer relações inicialmente individuais com cada objeto ou ser que nomeia, ampliando-as mais tarde" (1955, p.05). A função da leitura é contribuir para que o ser se torne sujeito de sua própria história a 
partir da reflexão do texto literário. A obra literária é um objeto social e como tal possui uma dimensão político-ideológica que precisa ser considerada, portanto deve-se ensinar literatura para trazer o homem a sua realidade e não para fugir dela. Literatura não é escape, literatura é enraizamento.

Nas séries iniciais, acima do ensino conteudístico e das demais leituras, o que deve predominar é a leitura do texto literário. O texto literário apela para as emoções, a fantasia, o intelecto e apresenta o mundo a partir de uma perspectiva lúdica e estética, espelho do mundo infantil. "Assim, uma educação que se queira libertadora, humanizante e transformadora passa, necessariamente, pelo caminho da leitura" (FRANTZ, 2005, p.21). O fenômeno literário está inserido num contexto social mais amplo e estabelece relações peculiares com o real. Ao mesmo tempo em que é representação deste, a literatura é também interrogação da realidade, assumindo então uma função social crítica importante. De modo geral, a literatura permite ao leitor descobrir novos sentidos para a realidade, ampliando e enriquecendo a sua percepção do ser humano e de si mesmo.

Mediante o poder de sedução empreendido pela tessitura literária, o leitor é convidado a ir ao encontro do misterioso, do desconhecido, do fantástico. De fato, não há surpresa na premissa de que a literatura é vista como o principal meio de acesso à descoberta do mundo-homem e do homem-mundo, que voa se delineando à medida em que o leitor toma consciência de si mesmo e do outro:

Não é novidade o fato de que a leitura literária pode se converter num exercício de descoberta do mundo e de si mesmo. [...]. A constituição do mundo interior do sujeito é fruto de um processo de conscientização de si mesmo, da sua contingência pessoal, assim como das circunstâncias que o cercam (AGUIAR, 2006, p.210).

A construção/formação do aluno se dá quando ele se mostra capaz de mergulhar nas possibilidades significativas do texto literário e, então, fazer analogias entre a ficção e sua realidade. Nesse sentido, Lajolo complementa a afirmação acima, enfatizando que "ou o texto dá um sentido ao mundo, ou ele não tem sentido nenhum" (1993, p.15). Para isso, a figura mediadora do professor é fundamental. Fazendo uma referencia mítica, o professor é como Ariadne, que concede seu fio "intelectual” para que o aluno-Teseu enfrente o Minotauro e consiga escapar do labirinto-texto.

Destoante do pensamento geral, a literatura não se transfigura em jogo enigmático, cujo "decifra-me” decide pela salvação ou sentença do edipiano leitor ante 
o "texto-esfinge". Seu significado não se antecipa ao indivíduo, nem mesmo se origina no próprio texto. O texto literário só produz seu efeito quando é lido, só se atualiza no leitor:

Ler não é decifrar, como num jogo de adivinhações, o sentido de um texto. É, a partir do texto, ser capaz de atribuir-lhe significação, conseguir relacioná-lo a todos os outros textos significativos para cada um, reconhecer nele o tipo de leitura que seu autor pretendia e, dono da própria vontade, entregar-se a essa leitura, ou rebelar-se contra ela, propondo outra não prevista (LAJOLO, 1982, p.59).

Isso não quer dizer, no entanto, que uma única leitura do texto literário o esgote em sua plurissignificação. Na verdade, o que torna literária uma obra é a sua capacidade de suportar várias interpretações. Dizer que determinado texto da literatura foi absolutamente lido é perder sua essência. A diferença primordial entre a leitura literária e a convencional é justamente o fato de que, naquela, sempre sobra uma gota dessa fonte para ser bebida, "numa nova leitura que se faça, ou numa interpretação que surja, vinda de um 'leitor flutuante', atento à força da identificação” (LOIS, 2010, p.42).

\section{Literatura não é Gramática!}

A prática da leitura literária só ganha espaço no ensino por meio da disciplina de Língua Portuguesa, a depender da disposição curricular e do conhecimento pedagógico do professor. Entretanto, o sistema escolar organiza seu tempo de forma fragmentada, em matérias estanques, ainda que se considerem temas transversais ou trabalhos interdisciplinares. Nesse contexto, o tempo reservado para a leitura da literatura se torna bastante escasso; na verdade, ele é insuficiente para atender à demanda necessária da leitura do aluno.

De suma importância se converte a eleição de práticas literárias na escola como núcleo do trabalho docente, e não os conteúdos das disciplinas que contribuem para a construção dessa leitura. Esse tipo de leitura não pode ser feita de forma sistemática e em nome do prazer absoluto de ler. Deve-se compreender que o letramento literário é um encargo inescapavelmente escolar; o que está em jogo não é a escolarização - ou não - da literatura feita pela escola, e sim a maneira como fazê-la sem que se perca sua essência. Assim, para formar leitores capazes de experienciar toda a força humanizadora da leitura literária, não basta apenas ler, pois não existe leitura simples. É justamente para ir além da simples leitura que o letramento literário é essencial no processo educativo: "o estudo crítico e comparativo do texto como um todo [...] se apresenta 
como uma forma de desmitificar e desautorizar modelos [...]" (MAGNANI, 2001, p.138).

A leitura literária não pode ser impositiva e meramente formal, haja vista o caráter polissêmico do discurso literário. Por outro lado, o ensino da língua, quando se propõe a explorar as potencialidades do texto literário, adota uma postura deturpada do que seria a manifestação coerente do fenômeno literário. A primeira providência tomada, ao se trabalhar literatura na sala de aula, é a apresentação da leitura unilateral do professor. Dessa única visão de entendimento, parte-se para a "dissecação" do texto - as conhecidas fichas de leitura -, cujo intuito único é tão somente a análise estrutural da obra, salvo as raríssimas vezes em que se estudam seus componentes estéticoliterários. Em consequência disso, perde-se a maior porção do texto, que, por certo, constitui-lhe sua totalidade: elementos estilísticos, a manipulação da linguagem, as entrelinhas e - sobretudo - as conexões que se estabelecem com o real: "A literatura é para ser lida e compreendida como uma arte. Entretanto, produto concreto da realidade, ela é um conhecimento que não pode limitar-se a uma análise estético-formal que se distancia do universo humano, estrutura basilar de sua existência" (LIMA, 1996, p.43).

Como nas aulas de literatura, percebe-se que o aluno ainda não é tratado como sujeito, e sim como um mero receptor do conteúdo, texto ou das informações do professor. E baseando-se na leitura literária, quando a última pergunta de um questionário solicita a posição do aluno, esta deve ser tratada como um ponto de vista ilustre que não se deve refutar, ou seja, qualquer colocação edita/escrita deve ser aceita, já que a pergunta é aberta à resposta livre. O professor não deve procurar pelas respostas certas, mas sim pela interpretação a que o aluno chegou e o percurso do pensamento que o levou a tal conclusão. Desse modo, cabe ao professor aceitar como válidas as impressões de leitura dos alunos, sem maior questionamento, porque elas são o único produto legítimo do sentimento inefável que une obra e leitor, pois o objetivo da avaliação é engajar o estudante na leitura literária e dividir esse engajamento com o professor e os colegas.

Outra constante na prática da leitura literária é a estratégia do texto como pretexto. Trata-se do uso de textos literários para se ensinar escolas literárias, regras de gramática e tópicos de redação. Nitidamente, essa é uma atitude que se distancia do propósito desse tipo de leitura, que é a fruição estética, prazerosa e espontânea. O ensino de literatura que se comporte de tal maneira, certamente, resultará no assassinato de todo encanto e beleza que a obra literária poderia despertar no leitor, se este a reino da palaura: reflexões sobre a leitura literária. Saulo Lopes de Sousa. p. 138 - 147. 
encarasse livre de pretensões didáticas ou gramaticais, pelo simples prazer de descobrila no que tem de mais belo.

Não menos importante, os livros didáticos e paradidáticos também desconstroem o ideal de leitura literária. Em sua maioria, os livros didáticos já celebrizaram a sessão destinada à literatura: texto (geralmente um recorte de obra); questionário de compreensão/interpretação (fichas de leitura); estudo da gramática e produção textual. Tal lógica trai a natureza do texto literário e produz a imagem de que a leitura da obra literária se limita a isso, e somente a isso: trechos de obras, resolução de questões e estudo gramatical. É preciso entender o valor do livro literário e não transformar o momento prazeroso da leitura numa aula maçante de como assassinar no aluno o deleite e a vontade de ler literatura.

Conforme Zilberman, "tudo que mudou parece ter mudado para melhor, menos a escola com suas conseqüências" (2009, p.13). Em verdade, mesmo com todo o progresso científico-tecnológico por que passa a sociedade, o qual desenvolve a modernização das instituições educacionais e, ao mesmo tempo, monopoliza as primazias dos alunos, a escola continua a reproduzir o ensino mecanicista voltado unicamente para o tradicionalismo. Por sua vez, para os professores e estudiosos da área de Letras, a literatura só se mantém na escola por força da tradição e da inércia curricular, uma vez que a educação literária é um produto do século XIX, que já não tem razão de ser do século XXI. Muitas acham que já sabem de tudo, por isso a disciplina é dispensável; outros são indiferentes, já que acreditam que o papel da literatura é apenas o de reforçar a leitura. Por último, há aqueles que desejam estudar a disciplina, todavia não possuem referências culturais para aprendê-la ou não têm acesso a um ensino de qualidade.

Pela consciência de que a leitura é a via de acesso ao conhecimento, a escola não pode tornar-se um cárcere, tolhendo seus alunos de se emanciparem na aprendizagem da leitura no cultivo do gosto pelo literário. Passando obrigatoriamente pela concepção de escola e de sociedade que se almejam, a formação do gosto literário envolve a diversidade de princípios norteadores dos critérios de seleção e utilização dos textos e da reflexão sobre a formação do gosto das pessoas-aluno, não só para um vir-a-ser, mas também para um aqui e agora, principalmente político. “As leituras de que o aluno gosta podem ser trazidas para a sala de aula, como ponto de partida para a reflexão, análise e comparação com outros textos (inclusive os produzidos pelos próprios alunos)" (MAGNANI, 2001, p.138). O gosto literário não é algo inato, um dom. Na reino da palaura: reflexões sobre a leitura literária. Saulo Lopes de Sousa. p. 138 - 147. 
verdade, o gosto pelo literário é uma construção, em que o professor tem papel decisivo. Está, portanto, a cargo do professor trabalhar para que essa construção se efetive em sua prática profissional $^{1}$.

A prática pedagógica do professor revela necessariamente a sua visão de educação. Nesse sentido, é certo afirmar que, se o docente se orienta por uma concepção emancipatória de educação, ele adotará práticas de ensino igualmente emancipatórias. $\mathrm{O}$ professor de literatura é um intermediário, auxiliar entre o livro e o leitor, isso não significa que o professor deverá ler pelo aluno, mas sim ler com o aluno. Para tanto, o professor deve reservar um momento de leitura nas suas aulas, pois consoante Martins (2006, p.25), "no contexto brasileiro, a escola é o lugar onde a maioria aprende a ler e escrever e muitos têm sua talvez única oportunidade de contato com os livros". É preciso romper com o comodismo literário na prática docente, quer dizer, é necessário diversificar a apresentação do texto literário, sua leitura e as abordagens didáticas.

É impossível aceitar que a simples atividade de leitura seja considerada atividade escolar de leitura literária. $\mathrm{Na}$ verdade, apenas ler não é a face mais visível da resistência dão processo de letramento literário da escola. Por trás desse letramento, encontram-se pressuposições sobre leitura e literatura que não são discutidas. Uma é a de que os livros falam por si mesmos ao leitor; outra é a de que ler é um ato solitário.

Magnani assim expõe:

\begin{abstract}
A leitura não acontece isolada na sala de aula, e deve estar articulada às práticas de produção e análise de textos, para que se caracterize como conhecimento de opções, que à medida que se tornam conscientes, podem ir sendo utilizadas pelos alunos para seus propósitos de leitores e autores (2001, p.105).
\end{abstract}

Então, um bom leitor é aquele que agencia com os textos os sentidos do mundo, compreendendo que a leitura é um concerto de vozes e nunca um monólogo. Outra ideia é de que é impossível expressar o que se sente na leitura dos textos literários. Não haveria palavras para descrever os sentimentos despertados pelo texto literário, mas compartilhar os seus sentidos faz o texto literário ser tão significativo para os leitores.

\footnotetext{
1 Existe o pensamento distorcido de que somente os docentes de Língua Portuguesa têm a responsabilidade de ensinar leitura a seus alunos. Como toda disciplina carece da capacidade interpretativa do discente, indispensável à compreensão tanto do conteúdo exposto oralmente quanto do conhecimento registrado nos livros, ensinar a ler se torna uma tarefa de todo professor, não sendo exclusividade apenas do de Língua Portuguesa, quase sempre responsabilizado pela dificuldade do aluno em interpretar questões de outras matérias. Em suma: todo professor é professor de leitura!
} 
Como forma de se intervir na defasagem de leitura literária no ensino de literatura, a proposta do letramento literário tem como objetivo construir uma comunidade de leitores, os quais angariarão novos repertórios e quadros culturais, movendo-se no mundo e se autoedificando. Para tal concretização, é salutar que o ensino de literatura promova um movimento continuo de leitura, partindo do conhecido para o desconhecido, ou seja, do simples para o complexo, com o intuito de ampliar e consolidar o meio cultural do aluno.

Atribui-se essa intitulação - letramento literário - por não se tratar da conquista da habilidade de ler e escrever, e sim da apropriação da escrita e das práticas que a ela se vinculam. O texto literário não aprisiona dentro de si o brilho, ao contrário, libera conhecimentos e magia a cada leitura feita. E é nessa leitura que se encontra um pouco de cada um, do passado e da comunidade a qual o ser humano é partícipe. Isso acontece porque a literatura é uma experiência que deve ser realizada.

Neste exercício, pode-se mergulhar na fantasia e ser outro, viver como outro, romper com a barreira do espaço-tempo e continuar sendo o que se é. É por essa função, de tornar o mundo compreensível, transformando a materialidade em palavras de cores, odores, sabores e formas, que a literatura precisa ter um espaço especial nas escolas.

Além de se deleitar e fruir coma estética da prosa ou da poesia, o leitor de literatura também se posiciona ante a obra literária, refletindo seus mecanismos de leitura, investigando ideologias e valores, descortinando sentidos. É a essa aprendizagem crítica da leitura literária, mediante o contato íntimo com o texto, principiador da experiência estética, que se denomina letramento literário. É preciso constituir a literatura no ambiente escolar naquilo que ela também é fora dele: uma chance única de ler e escrever o mundo e o homem. Sendo assim. O exercício do letramento literário assemelha-se à invenção da roda: "Ela precisa se inventada e reinventada em cada escola, em cada turma, em casa aula" (COSSON, 2009, p.120). Na constante reinvenção daquele, que sempre ocorrerá com empecilhos, o ensino de literatura se torna a gestação do aluno-leitor apto a "dialogar no tempo e no espaço com sua cultura, identificando, adaptando ou construindo um lugar para si mesmo" (COSSON, 2009, p.120).

Portanto, a leitura da obra literária é um exercício indispensável para a constituição de leitores, necessariamente, por conceder a possibilidade de esse mesmo reino da palaura: reflexões sobre a leitura literária. Saulo Lopes de Sousa. p. 138 - 147. 
leitor atingir um nível mais elevado de conhecimento crítico do mundo, além de tornálo intelectualmente autônomo e humanizado. Alimento da alma, a literatura pode - e deve - ser apresentada aos alunos, principalmente da educação básica, como um modo sedutor e condicionado à descoberta. Para isso, a postura mediadora do professor de literatura é essencial. Ele tem nas mãos o poder de construir leitores, a partir do barro de sua ignorância, tornando-os essências libertas do pó.

\section{Referências}

AGUIAR, Vera Teixeira de; MARTHA, Alice Áurea Penteado. (Orgs.). Territórios da leitura: da literatura aos leitores. São Paulo: Cultura Acadêmica, 2006.

CEREJA, William Roberto; MAGALHÃES, Thereza Cochar. Literatura brasileira. São Paulo: Atual, 1995.

COSSON, Rildo. Letramento Literário: teoria e prática. São Paulo: Contexto, 2006.

FRANTZ, Maria Helena Zancan. O ensino da literatura nas séries iniciais. 4. ed. Ijui: Ed. Unijui, 2005.

FREIRE, Paulo. A importância do ato de ler: em três artigos que se completam. 23. ed. São Paulo: Autores Associados: Cortez, 1989.

LAJOLO, Marisa. O texto não é pretexto. In. Zilberman, Regina. Leitura em crise na escola. Porto Alegre: Mercado Aberto, 1982.

Do mundo da leitura para a leitura do mundo. São Paulo: Ática, 1993.

LIMA, Adolfo de. Práticas educacionais e ensino de literatura brasileira. Recife: Ed. Universitária da UFPE, 1996.

LOIS, Lena. Teoria prática da formação do leitor: leitura e literatura em sala de aula. Porto Alegre: Artmed, 2010.

MAGNANI, Maria do Rosário Mortatti. Leitura, literatura e escola: sobre a formação do gosto. São Paulo: Martins Fontes, 2001.

MARTINS, Maria Helena. O que é leitura. 19ª ed. São Paulo: Editora Brasiliense, 2006. VARGAS, Suzana. Leitura: uma aprendizagem de prazer. Rio de Janeiro: José Olympio, 1955.

ZILBERMAN, Regina; RÖSING, Tania (Orgs.). Escola e leitura: velha crise, novas alternativas. São Paulo: Global/ALB, 2009. 